\title{
Second Summer in NW Indian Ocean
}

\section{Kern E. Kenyon}

4632 North Lane, Del Mar, San Diego, USA

Correspondence to: Kern E. Kenyon, Kernken@aol.com

Keywords: NW Indian Ocean, Bi-Seasonal SSTs, Second Summer in Fall

Received: July 24, $2017 \quad$ Accepted: August 14, $2017 \quad$ Published: August 17, 2017

Copyright $\odot 2017$ by authors and Scientific Research Publishing Inc.

This work is licensed under the Creative Commons Attribution International License (CC BY 4.0).

http://creativecommons.org/licenses/by/4.0/

\section{(c) (i) Open Access}

\section{ABSTRACT}

Two independent SST atlases have confirmed that there is a double seasonal signal in the surface layer of the northwestern Indian Ocean. The area enclosed by the $80 \mathrm{~F}$ isotherm increases from January to a maximum in May followed by a decrease, a cool-down, to August, which has been explained recently. Then there is a second maximum of warm surface area in October/November, called a "second summer" for convenience. A hypothesis is proposed to explain this unusual second summer feature by extrapolating from available data. During July, August and September, the sea level slopes downward from the equator to the north providing a horizontal force to drive the warm surface water accumulated in the equatorial region back into the NW Indian Ocean basin. New observations are needed to check up on the hypothesis.

\section{INTRODUCTION}

Two independent SST data sets $[1,2]$ have verified that there is a double seasonal signal in the surface layer of the northwest Indian Ocean: two "summers" and two "winters" [3] in a single year. "Summer" is meant a time when the area of highest sea surface temperatures reach a maximum percentage of the whole area of the northwestern Indian Ocean. April/May and October/November are the mid-points of the two summers; "winters" are January and August where the areas of warmest temperatures shrink to a minimum. Hardest to understand perhaps is how October/November turns out to be a "summer" in the northern hemisphere. What is attempted below is to propose a hypothesis to begin to explain such an unusual feature, which so far has not been found in any other oceans.

Given that the first "summer" peaks in April/May, followed by a marked cool-down, this cool-down itself is a big surprise as discussed recently [4], because one does not anticipate a major cooling of the sea surface just when the sun is strongly pumping energy into the top $100 \mathrm{~m}$ normally resulting in a warming up of the water.

Both SST atlases agree in suggesting that the spring cool-down starts at the African coast (Somalia) and then spreads north and east from there, apparently driven by a force. A reasonable suggestion for the driving force is a horizontal pressure gradient, related to the northward large-scale temperature gradient in 
the surface layer (cold in the south monotonically increasing to warm in the north) that extends right across the equator off Africa in spring. Such a horizontal temperature gradient is inherently unstable: the cold water wants to move toward the equator, pushing the warm water out of the way, all within the surface layer.

Whether or not the physical driving mechanism just mentioned is acceptable or can be verified, the spring cooling of the surface layer is an observed fact, and therefore can serve as a starting point upon which to build an approach toward an explanation of the second summer (also an observed fact).

\section{PRELIMINARY ARGUMENTS}

When the cooler water advances from the west into the interior of the ocean basin, during the spring cool down, the warmer water on the surface retreats (shrinks in area), according to the SST atlases. At first it would then seem to be a necessity that at least part of this retreating warm surface water should go south and cross the equator somewhere on the eastern side of the basin. Since the surface layer is held up by the buoyancy force associated with the thermocline, which exists almost everywhere in the open ocean, the crossing of the equator is consistent with conservation of mass in the surface layer. Colder water encroaching from the west would push warmer water to the east and then south due to contact with the continental boundary (India).

However, conservation of mass applied in this way is restrictive because of an unstated assumption: the vertical thickness of the surface layer stays constant. Misleading predictions could be the result [4].

Another possibility exists that is consistent with observations: through convergence the pushed out of the way warm surface water could bunch up causing the surface layer to expand vertically downward, and the surface "footprint" to shrink, thereby releasing the stringent condition from a horizontally applied conservation of mass that an equatorial crossing be mandatory.

One way or the other, at some point around August/September the cool down stops and turns around into a warming up. What might be happening is educated speculation, but evidently the horizontal forcing mechanism behind the cooling somehow decreases in strength or ceases altogether while another force of opposite sign takes over, sending the warm water north and west counterclockwise back into the basin, increasing again its high percentage of the total surface area.

\section{HYPOTHESIS}

First, the hypothesis is stated. Beginning in July and continuing in August and September, the sea level slopes down to the north from the equator, mainly in the eastern half of the NW Indian Ocean basin. It is this downward slope of the sea surface that produces a horizontal force that drives the warm surface water to the north during these months.

Ships at sea cannot measure sea level directly, and satellite methods are forbiddingly complicated at present for a person outside the field to get involved. SST observations made from ships can be used to make inferences about sea level by means of the thermal expansion concept. If no other processes get in the way, warmer water will stand higher than colder water because of thermal expansion, the warmer water initially being caused by absorbed solar radiation.

Figures 1-3 show the SST distribution over the whole Indian Ocean for July, August and September, respectively, reproduced from H. O. 225 [1]. In all three months the charts make it clear that the highest sea surface temperatures are along the equator, and the temperatures decrease northward over most of the open ocean regions. For the other nine months that same convincing picture does not hold up at all. Not only that, but the temperature contours which start out in July being parallel to the equator, between $80 \mathrm{E}$ and 60E, move away to the north and west in August and further yet in September. During the northwest movement the temperature between the equator and the $80 \mathrm{~F}$ contour decreases by a couple of degrees from $82.5 \mathrm{~F}$.

Where does the suggested pooling or bunching up of the warm water come from? Evidence to support that idea is a bit sketchy, so more is needed in the future. One of the two equatorial hydrographic sec- 


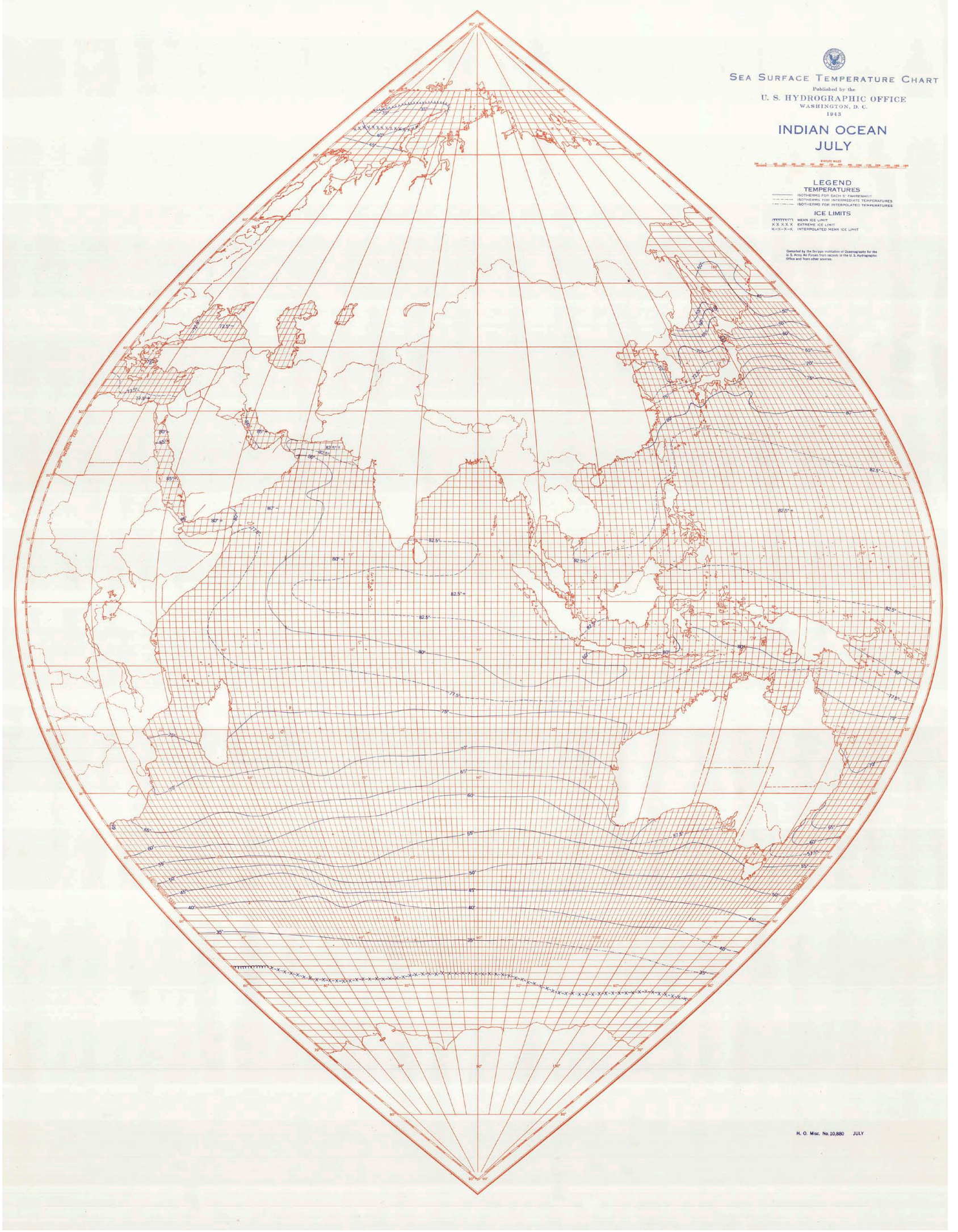

Figure 1. Sea surface temperature for the Indian Ocean in July. From Reference [1]. 


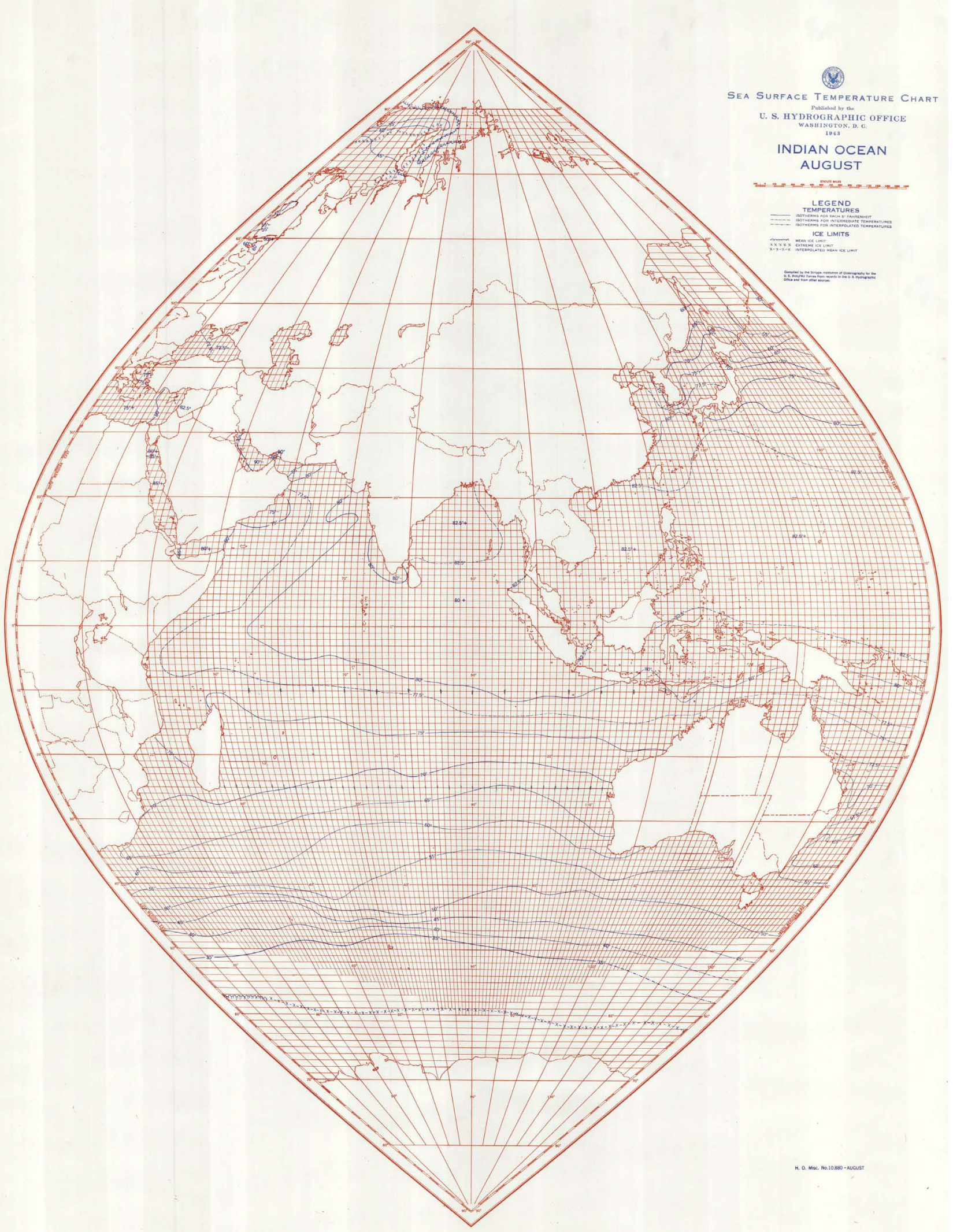

Figure 2. Sea surface temperature for the Indian Ocean in August. From Reference [1]. 


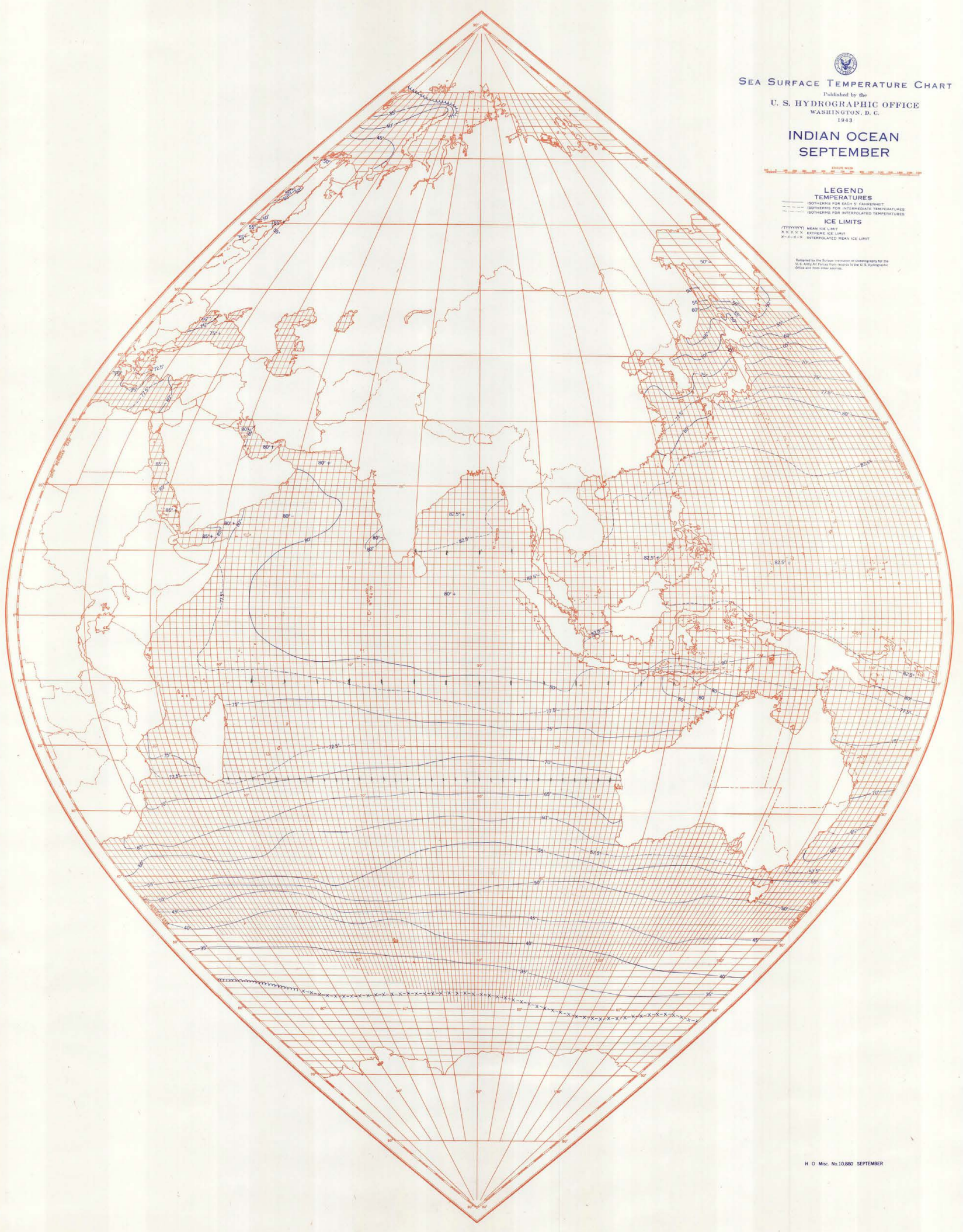

Figure 3. Sea surface temperature for the Indian Ocean in September. From Reference [3]. 
tions in the Indian Ocean atlas [2] took place in July (1962). It shows a deep mixed layer (100 m) in a large longitude band centered around 80E. [The other equatorial section was in March/April (1963) and has a much shallower mixed layer depth $(50 \mathrm{~m})$.] It is true that over $90 \%$ of the absorbed solar radiation occurs in the top $100 \mathrm{~m}$ of ocean water, but it is not believable, perhaps, that the sun by itself could make a mixed layer of uniformly warm water $100 \mathrm{~m}$ thick, particularly on the equator and in July! Then the bunching up notion springs to my mind. Others might think of wind stirring, so that avenue should be explored as well.

Suppose, because it is not known at this time, that in July, around 70E, a $100 \mathrm{~m}$ mixed layer maintains a constant depth from the equator northward over a sizeable band of latitudes. Then the sea level is predicted to decrease northward by thermal expansion because the surface temperature decreases northward. More than likely, though, the $100 \mathrm{~m}$ mixed layer depth might be found to gradually decrease with increasing latitude, having the effect of magnifying further the downward sea slope to the north. Less warm water in a vertical column produces less thermal expansion of the sea surface.

After the warm water spreads out back over the sea surface during the second summer in October/November, there is a gradual lowering of the sea's temperature until January while heat from the ocean is given up to the atmosphere by conduction and evaporation. This assumption appears logical, but documentation is lacking.

\section{CONCLUSION}

Northwestern Indian Ocean's second summer, in October/November, is explained by a hypothesis, which is inspired by existing data. Sea level slopes down toward the north, being relatively high at the equator and decreasing monotonically with increasing latitude, from July through September. Thus a northward horizontal force is created in the surface layer that drives warm water, temporarily stored in the equatorial region, north and west to cover a large percentage of the surface area of the ocean basin in October/November. To try to verify this hypothesis new ocean observations will be required.

\section{REFERENCES}

1. U.S. Navy Oceanographic Office (1944) World Atlas of Sea Surface Temperatures. 2nd Edition, H.O., Washington, D.C.

2. Wyrtki, K. (1971) Oceanographic Atlas of the International Indian Ocean Expedition. National Science Foundation, Washington, D.C.

3. Kenyon, K.E. (2014) Northwest Indian Ocean's Spring Cooling. Natural Science, 6, 760-766. https://doi.org/10.4236/ns.2014.610076

4. Kenyon, K.E. (2017) NW Indian Ocean's SSTs Are Bi-Seasonal. Natural Science, 9, 216-218. https://doi.org/10.4236/ns.2017.97021 
Submit or recommend next manuscript to SCIRP and we will provide best service for you:

Accepting pre-submission inquiries through Email, Facebook, LinkedIn, Twitter, etc.

A wide selection of journals (inclusive of 9 subjects, more than 200 journals)

Providing 24-hour high-quality service

User-friendly online submission system

Fair and swift peer-review system

Efficient typesetting and proofreading procedure

Display of the result of downloads and visits, as well as the number of cited articles

Maximum dissemination of your research work

Submit your manuscript at: http://papersubmission.scirp.org/

Or contact ns@scirp.org 